\title{
It's about More Than Just Baby Teeth: An Examination of Early Oral Care in Canada
}

\author{
Leonard Smith ${ }^{1}$, Larry Katz ${ }^{2, *}$, Herbert Emery ${ }^{3}$, Jackie Sieppert ${ }^{4}$, Zoe Polsky ${ }^{5}$, Kimberly Nagan ${ }^{6}$ \\ ${ }^{1}$ Department of Pediatrics in the Faculty of Medicine, University of Calgary, Calgary, T2N 1N4, Alberta, Canada \\ ${ }^{2}$ Faculty of Kinesiology, University of Calgary, Calgary, T2N 1N4, Alberta, Canada \\ 3Department of Economics, University of Calgary, Calgary, T2N 1N4, Alberta, Canada \\ ${ }^{4}$ Faculty of Social Work, University of Calgary, Calgary, T2N 1N4, Alberta, Canada \\ ${ }^{5}$ Kinesiology, McGill University, Montreal, H2W 1S4, Quebec, Canada \\ ${ }^{6}$ Research Associate, University of Calgary, Calgary, T2N 1N4, Alberta, Canada
}

Copyright () 2014 Horizon Research Publishing All rights reserved.

\begin{abstract}
It may come as a surprise to the public and to medical practitioners that the most common infectious disease in young children is dental decay and that oral health is the most prevalent unmet healthcare need of children. Children who present with early childhood caries (ECC) can suffer from pain, sleeplessness, malnutrition, difficulty playing, struggles in school, and toxic stress. Although it is almost completely preventable through low-cost preventive measures, prevalence is very high in Canada affecting over one quarter of children. Several factors interact on different levels (child, family and community) to create a situation in which ECC prevails. Recommendations for prevention are presented and include early visits to a dentist, dental care as part of prenatal care, interdisciplinary collaboration across health and social services, as well as many others.
\end{abstract}

Keywords Early Childhood Caries, Child, Oral Health, Prevention, Canada

\section{Introduction}

It may come as a surprise to the public and to medical practitioners that the most common infectious disease in young children is dental decay [1] and that oral health is the most prevalent unmet healthcare need of children [2]. In fact, the number of children with early childhood caries (ECC) exceeds the number of children with asthma five fold [1]. Even in its simplest manifestations, ECC could require surgery under a general anaesthetic. One in 100 children under age 5 in Canada will have this surgery making it the leading cause of day surgery in children [3]. The public cost of the hospital care alone for oral surgery in children ages 1-5 is over \$21 million annually; a figure which excludes the associated costs of anaesthesia, surgeons and travel costs $[3,4]$. Unlike many other infectious diseases, ECC is almost completely preventable at very little cost through proper oral hygiene and feeding practices. So why, then, do Canadians pay over $\$ 1500$ per case to treat ECC [3]?

For better or for worse, the Canada Health Act ensured that the acute care illness treatment system centered on doctors and hospitals would be tasked with looking after the health promotion and development of our children. The Act does not cover dental care and has lead to the belief that oral health should be considered apart from overall health; however, consider that the mouth is the gateway to the body and what affects the mouth affects the whole person. The exclusion of dental care from the overall medical system, the lack of dental education in medical school, and poor collaboration between dentists, doctors and allied health professionals have contributed to the social failure reflected in ECC.

ECC has been dismissed by the medical system as a dental problem not a health problem, and service providers have failed to appreciate the vital link between oral health in children and overall wellbeing. Furthermore, the link between health service use and oral health is underappreciated, as dental pain is one of the leading causes for emergency room visits in paediatric hospitals [5]. Untreated, children with ECC suffer from toothache (acute and chronic), sleep deprivation, malnutrition, difficulty playing, struggles attending school [6], failure to thrive [7], deficiency in hemoglobin levels, decreased serum albumin and ferritin [8], and in extreme cases, death [9]. Ironically, some of the results of ECC are also the cause of the problem. Children who lack proper nutrition do not possess the vitamins and minerals to maintain a healthy oral environment [10,11].

These assaults are fundamentally harming physical and mental development which can cause children to experience what is known as toxic stress; strong, frequent or prolonged activation of the body's stress management system without adequate adult support [12]. Toxic stress is known to cause permanent architectural changes in the brain that lead to 
higher incidences of addictive behaviors, obesity, diabetes, cardiovascular disease, anxiety disorders, suicide, and incarceration [13-16]. This tells us that early oral health care is about more than just baby teeth, and moreover, it is most definitely a health issue and not just a dental issue. Unfortunately, there is a gap between the important role that healthy baby teeth play in oral and overall development and the care these small teeth receive at home and in the community.

Unique to this particular infectious disease, is that it can be almost completely eliminated through prevention. Furthermore, prevention comes at little cost to families and the health care system. Despite this, the prevalence of ECC in Canada remains high [17]. While epidemiologic data describing ECC in the general Canadian population are sparse, Canadian caries prevalence trends are similar to those in the United States [17]. Rates of caries in permanent teeth continue to decline, however, the prevalence of childhood caries in children ages 2 to 5 years has increased from $24 \%$ in 1988 to $28 \%$ in 2004 [18-20]. Nearly 20\% of children between the ages of 2-5 years old who present with ECC do not receive treatment [18]. Treatment is expensive and risky as it often involves general anesthesia, and, furthermore, does little in the long term as the bacteria that causes ECC is still present in the body after the affected tooth/teeth are restored or removed. This indicates that prevention is preferable to treatment.

Educational efforts, community awareness and changes in public policies are required as ECC remains a complex problem necessitating multifaceted intervention. Several actions (or inactions) on multiple levels interact to create an environment that allows for poor oral health in a child. A conceptual model has been developed [21] which proposes that children's oral health is influenced on three levels: child, family, and community (see Figure 1). What follows are suggestions to preventing ECC on all three levels.

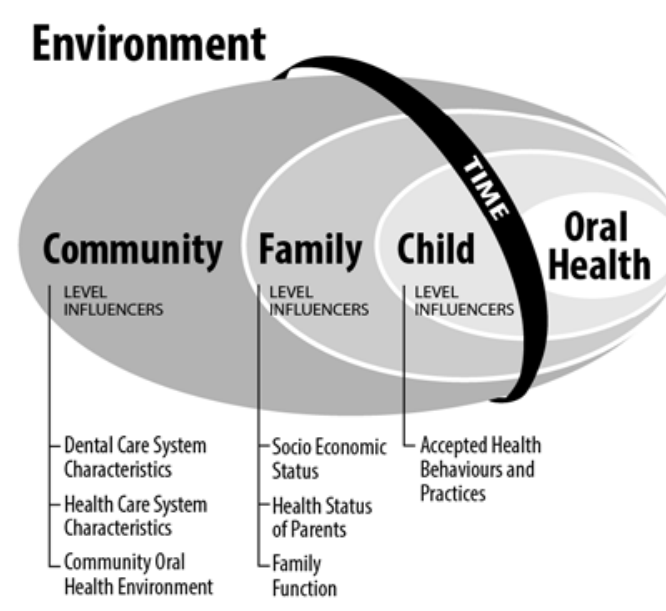

Figure 1. Child, family, and community influences on oral health outcomes of children. Adapted from Fisher-Owens, et al. (2007).

\section{Preventive Strategies}

\subsection{Child Level Preventive Strategies}

Prevention of ECC through the elimination of child-level or individual influences include simple, low-cost tasks such as daily wiping of gums and brushing teeth with an appropriate sized toothbrush and a small amount of fluoridated toothpaste, reducing the amount of sugary foods consumed, and eliminating the use of bottles and/or no-spill cups of milk, formula or juice in bed. Educating caregivers on the ill-effects of pre-chewing food for children to reduce the chance of sharing oral bacteria is crucial. A visit to a dentist by the first birthday to assess the oral condition and prevent progression if decay is present is the current recommendation made by the Canadian Dental Association [17] as delayed first dental visits are directly correlated with increases in ECC [22].

Behavior modification in children is a viable ECC prevention method. The first step in getting a person to process the information in a behavior change message is to gain and maintain that person's attention [23]. Once attentive, Social Cognitive Theory proposes that enhanced skills and confidence (self-efficacy) in doing the new behavior can lead to the change [24]. Videogames can fulfill both of these requirements. Today's youth are exposed to videogame entertainment at an early age, thereby making it recognizable, familiar and attention grabbing. Additionally, many videogames are created with levels and rewards, creating a form of focus and goal-setting for the player and enhancing skill development through progression. Studies examining health-related behavior change videogames for children and youth have shown that it is possible to achieve positive outcomes [25,26]. However, to be successful, behavior change videogames must be designed with a strong foundation in psychological and instructional theory [26]. Designing a simple videogame (or app that requires minimal motor skills) for very young children could be one method to engage and empower children in their own healthy futures.

\subsection{Family Level Preventive Strategies}

On a family level, important influences to address include the health status of the parents, socioeconomic status (SES), social support, coping skills, physical safety, culture, and health behaviors and practices. Many of these factors interact to either improve or worsen outcomes. Tooth development begins in utero; therefore inclusion of oral examinations as a part of prenatal health is important. Furthermore, proper maternal nutrition benefits the developing fetal tooth buds and provides a good basis for the primary teeth [27]. Gomez and Weber [28] found that providing oral health education and treatment for pregnant women was successful in keeping their children free from caries through age three and a half as compared with a control group.

The family unit provides immediate role-modeling for the child and observed actions can have both direct and indirect impacts on children's oral health. Caregiver health status including oral, mental and physical health, influence how 
children see, understand and react to health care practices. Examples of supports to promote parental health include easily accessible community health and dental clinics, informal and formal social groups, access to fitness equipment and harmful behavior cessation counseling. Most communities have a community center that is available for both public and private events. Having a space to gather in which is close to home and can provide childcare is often the hardest challenge to overcome, especially for high risk individuals. Using such spaces for public health education and service delivery is a possible option.

Caregiver health and other social factors can impact the ability to provide adequate modeling and support to children financially. Providing financial support for those families who cannot afford proper nutrition and dental care is one step toward preventing ECC and many other deleterious health conditions. Children from low SES backgrounds show the highest ECC prevalence $[3,20,29-30]$ in part due to a lack of affordable preventive and treatment services [31]. However, providing financial assistance is only one piece of the puzzle. A study of 820 families who received one of two forms of financial assistance for dental care were surveyed. While 89\% stated that the financial assistance helped them to access services for oral care that they would otherwise not be able to use, only $44 \%$ actually used services within the previous 12 months [32]. Providing financial aid for dental care is only beneficial if services are accessible and accessed. A common problem reported is that dentists limit treatment of the beneficiaries of aid programs due to low payment rates, administrative hassles and missed appointments [33]. Changing the structure of how public dollars is spent on oral care to provide services such as very low-cost, easily accessible clinics rather than subsidies could increase user uptake and promote preventive rather than restorative care.

Resiliency and coping skills enable people to make healthy choices. Social support through family, friends and community provides such skills and is associated with better health [21]. Safe environments for caregivers and children are very important for proper health. Children with a history of maltreatment and neglect suffer disproportionately from ECC. A recent Canadian study examined a population of two to six year old children who had suffered some form of maltreatment and found that $57 \%$ of the maltreated children had ECC, compared with $30 \%$ of five year olds in the broader community [34]. Identifying those families in need of secure environments can prevent ECC. Furthermore, working with families who refuse oral treatment for their children should be a priority as oral neglect is a form of abuse. Reporting these families to the authorities is an option; however refusal for treatment may be as a result of the high cost/inaccessibility of treatment. Identifying these families and working with them to provide alternatives to dismissing the situation is necessary.

Finally, culture and family health practices influence oral health outcomes. The perceived importance of oral care, the foods consumed and the practices observed in the house can affect ECC. Studies from around the world show that children from immigrant populations and ethnic or cultural minorities report a higher prevalence of ECC than the population in which they live [19,35-39]. Wendt and colleagues [40] found that children in immigrant households had their teeth brushed less often, used less fluoridated toothpaste and had more visible plaque than children from non-immigrant households. Belonging to a culture where dental disease is endemic and therefore not seen as a concern, or where preventive care is not the norm may be reasons why some families choose not to access care [41]. Providing culturally appropriate educational material, taking into account language and imagery, targeted evidence, location for dissemination, and strategies that involve the broader culture [42] are important to consider.

\subsection{Community Level Preventive Strategies}

Community-wide prevention comes in the form of interdisciplinary collaboration, public health education programs and public policy at the various levels of government. Community-wide services should include preventive education and treatment from non-dental professionals such as primary care physicians, nurses and social workers. In 2003, The American Academy of Pediatrics created a policy stating that by age six months every child should have an oral health examination including a caries risk assessment from a qualified pediatrician or pediatric healthcare professional [43]. In addition to screening for oral health disease, doctors can take this opportunity to educate parents on the risk factors for caries even before a child's teeth begin to erupt. The doctor's office is an ideal screening venue as the majority of children will visit a doctor long before visiting a dentist [44]. However, a study of physicians indicated that the level of instruction in medical school was insufficient to provide such care [45]. Fortunately, it has been found that with only two hours of training, physicians were able to identify with adequate accuracy cavitated carious lesions in children's teeth and provide referral [46]. As such a minor amount of time is required to educate health professionals in identifying early oral deficiencies; continuing education is a viable avenue for training with the assistance of dental professionals. Greater collaboration between medical and oral health professionals is needed to provide adequate, holistic care.

Due to the myriad of variables that need to be considered, public health educational campaigns have been met with varying degrees of success. For many decades attention has been paid to developing the necessary skills (i.e. health literacy) to make positive health behavior choices [47]. More recently, social marketing - the marketing of ideas rather than hard goods - to promote socially beneficial behavior change has become a useful method for taking complex messages and translating them into concepts that large groups are able to digest and act upon [48]. Many health agencies worldwide use social marketing as a means for information dissemination [49] with great success due to its wide reach. Translating information to present it as relevant 
to a group is necessary to gain and maintain attention for behavior change. The following scenario is an example of how information can be translated to have a specific effect:

Most people know that the use of seat belts is successful in preventing serious injury if involved in a collision, much as most people know that appropriate dental hygiene is successful in the prevention of tooth decay. In a US National Highway Traffic Safety Administration survey, 56\% of those who stated that they rarely or never used seat belts agreed that they would prefer to be belted in an accident [50]. This highlights the problem faced by public health workers and policy makers: it is not that people need to be convinced of the benefits of seat belt use, rather that they need to be convinced that they may be in an accident [51]. The message here is that perhaps ECC prevention should not focus on the benefits of dental hygiene per se, but rather on convincing parents and policy-makers that young children develop caries.

\section{Conclusions}

Despite all of the evidence, scientific research does not always translate into public health policy. Policy-makers need to take the stand that ECC prevention is as important as cancer prevention (anti-tobacco campaigns) and alcoholism prevention (under-aged drinking campaigns). Provincial governments could include dental visits for children until the age of majority in the health services provided (as is done for eye care) to ensure adequate access to oral health care. Alternatively, dental care could be included in the fee schedule for well-baby doctor visits until age 12 months. In a study of over 1,000 Canadian dentists, 74\% responded that the government is not doing enough to promote oral health, and that public funding should be spent primarily on prevention [33].

In an economic climate where governments are remiss to allocate new dollars, the benefits of shifting funding from tertiary restoration to primary prevention should be highlighted. By not placing an importance on oral health and ECC prevention, the message being sent from those who have the power to educate, provide services and create policy is that it is not a priority for the greater community, and therefore, it does not need to be a priority for the individual. Oral health professionals, and undoubtedly those who have suffered from the effects of ECC, would likely state otherwise. It is about more than just baby teeth, and it is time that oral health care for young children is made a priority in Canada.

\section{REFERENCES}

[1] W. E. Nelson. Textbook of Pediatrics, WB Saunders, Philadephia, 1996.

[2] P. W. Newacheck, D. C. Hughes, Y. Y. Hung, S. Wong and J. J. Stoddard. The unmet health needs of America's children, Pediatrics, Vol. 105, No. Supplement 3, 989-997, 2000.
[3] Canadian Institute for Health Information. Treatment of preventable dental cavities in preschoolers: A focus on day surgery under general anesthesia, Ottawa, ON: CIHI, 2013.

[4] D. Moser. Early Childhood Caries and Hospital Resource Costs. Personal Communication, Calgary, Alberta, Health Information Reporting Group, Alberta Health Services, 2009.

[5] P. S. Casamassimo, S. Thikkurissy, B. L. Edelstein and E. Maiorini. Beyond the dmft: The human and economic cost of early childhood caries, Journal of the American Dental Association, Vol. 140, No. 6, 650-657, 2009.

[6] B. L. Edelstein, C. M. Vargas, D. Candelaria and M. Vemuri. Experience and policy implications of children presenting with dental emergencies to US pediatric dentistry training programs, Pediatric Dentistry, Vol. 28, No. 5, 431-437, 2006.

[7] A. Sheiham. Dental caries affects body weight, growth and quality of life in pre-school children, British Dental Journal, Vol. 201, No. 10, 625-626, 2006.

[8] M. Clarke, D. Locker, G. Berall, P. Pencharz, D. J. Kenny and P. Judd. Malnourishment in a population of young children with severe early childhood caries, Pediatric Dentistry, Vol. 28, No. 3, 254-259, 2006.

[9] J. Bingaman and B. L. Cardin. Preventing decay, preventing tragedy, Washington Post, March 18, 2007.

[10] P. P. Hujoel. Vitamin D and dental caries in controlled clinical trials: systematic review and meta - analysis, Nutrition reviews, Vol. 71, No. 2, 88-97, 2013.

[11] R. J. Schroth, J. Levi, E. Kliewer, J. Friel and M. E. Moffatt. Association between iron status, iron deficiency anaemia, and severe early childhood caries: a case-control study, BMC pediatrics, Vol. 13, No. 1, 22, 2013.

[12] National Scientific Council on the Developing Child. Excessive Stress Disrupts the Architecture of the Developing Brain: Working Paper \#3, Harvard University, Boston, 2005.

[13] Center on the Developing Child. In Brief: Early Childhood Mental Health, Harvard University, Boston, no date, Retrieved from: http://developingchild.harvard.edu/resources/briefs/inbrief_s eries/inbrief_early_childhood_mental_health/.

[14] H. M. N. McCain, J. F. Mustard and S. Shanker. Early Years Study 2: Putting Science Into Action, Council For Early Childhood Development, Toronto, 2007.

[15] J. P. Shonkoff. Investment in early childhood development lays the foundation for a prosperous and sustainable society,In: B. M. Tremblay RE, Peters RDeV, eds., Encyclopedia on Early Childhood Development [online]. Centre of Excellence for Early Childhood Development and Strategic Knowledge Cluster on Early Child Development, Montreal, Quebec, $2009 . \quad$ Retrieved from: http://www.childencyclopedia.com/documents/ShonkoffAN Gxp.pdf.

[16] J. P. Shonkoff, A. S. Garner, B. S. Siegel, M. I. Dobbins, M. F. Earls, L. McGuinn, J. Pascoe and D. L. Wood. The lifelong effects of early childhood adversity and toxic stress, Pediatrics, Vol. 129, No. 1, e232-e246, 2012.

[17] Canadian Dental Association. Report on early childhood caries, Committee on Clinical and Scientific Affairs, 2010.

[18] B. A. Dye, S. Tan, V. Smith, B. G. Lewis, L. K. Barker, G. 
Thornton-Evans, P. I. Eke, E. D. Beltrán-Aguilar, A. M. Horowitz and C.-H. Li. Trends in oral health status: United States, 1988-1994 and 1999-2004, Vital and health statistics. Series 11, Data from the national health survey, Vol. No. 248, 1, 2007.

[19] D. M. Krol and M. P. Nedley. Dental caries: state of the science for the most common chronic disease of childhood, Advances in Pediatrics, Vol. 54, No. 1, 215-239, 2007.

[20] N. Tinanoff and S. Reisine. Update on early childhood caries since the surgeon general's report, Academic Pediatrics, Vol. 9, No. 6, 396-403, 2009.

[21] S. A. Fisher-Owens, S. A. Gansky, L. J. Platt, J. A. Weintraub, M.-J. Soobader, M. D. Bramlett and P. W. Newacheck. Influences on children's oral health: a conceptual model, Pediatrics, Vol. 120, No. 3, e510-e520, 2007.

[22] R. J. Schroth and V. Cheba. Determining the prevalence and risk factors for early childhood caries in a community dental health clinic, Pediatric Dentistry, Vol. 29, No. 5, 387-396, 2007.

[23] R. E. Petty and J. T. Cacioppo. Communication and persuasion: central and peripheral routes to attitude change, Springer, New York, 1986.

[24] A. Bandura. Social foundations for thought and action: a social cognitive theory, Prentice Hal, Englewood Cliffs, NJ, 1986.

[25] T. Baranowski, R. Buday, D. I. Thompson and J. Baranowski. Playing for Real: Video Games and Stories for Health-Related Behavior Change, American Journal of Preventive Medicine, Vol. 34, No. 1, 74-82.e10, 2008.

[26] D. A. Lieberman. Management of chronic pediatric diseases with interactive health games: theory and research findings, Journal of Ambulatory Care Management, Vol. 24, No. 1, 26-38, 2001.

[27] N. Tinanoff and C. A. Palmer. Dietary Determinants of Dental Caries and Dietary Recommendations for Preschool Children, Journal of Public Health Dentistry, Vol. 60, No. 3, 197-206, 2000.

[28] S. Gomez and A. Weber. Effectiveness of a caries preventive program in pregnant women and new mothers on their offspring, International Journal of Pediatric Dentistry, Vol. 11, No. 2, 117-122, 2008.

[29] D. T. Kopycka-Kedzierawski, C. H. Bell and R. J. Billings. Prevalence of dental caries in Early Head Start children as diagnosed using teledentistry, Pediatric Dentistry, Vol. 30, No. 4, 329-333, 2008.

[30] S. Reisine and J. Douglass. Psychosocial and behavioral issues in early childhood caries, Community dentistry and oral epidemiology, Vol. 26, No. 1 Suppl, 32, 1998.

[31] J. J. Warren, K. Weber-Gasparoni, T. A. Marshall, D. R. Drake, F. Dehkordi-Vakil, D. V. Dawson and K. M. Tharp. A longitudinal study of dental caries risk among very young low SES children, Community dentistry and oral epidemiology, Vol. 37, No. 2, 116-122, 2009.

[32] M. S. Amin. Utilization of Dental Services by Children in Low-Income Families in Alberta, Journal of the Canadian Dental Association, Vol. 77, No. b57, 2010.

[33] C. R. Quiñonez, R. Figueiredo and D. Locker. Canadian dentists' opinions on publicly financed dental care, Journal of Public Health Dentistry, Vol. 69, No. 2, 64-73, 2009.

[34] N. Valencia-Rojas, H. P. Lawrence and D. Goodman. Prevalence of early childhood caries in a population of children with history of maltreatment, Journal of Public Health Dentistry, Vol. 68, No. 2, 94-101, 2008.

[35] B. L. Edelstein. Solving the problem of early childhood caries: a challenge for us all, Archives of Pediatrics and Adolescent Medicine, Vol. 163, No. 7, 667, 2009.

[36] H. F. Pollick, A. Rice and D. Echenberg. Dental health of recent immigrant children in the Newcomer schools, San Francisco, American Journal of Public Health, Vol. 77, No. 6, 731-732, 1987.

[37] C. H. Shiboski, S. A. Gansky, F. Ramos-Gomez, L. Ngo, R. Isman and H. F. Pollick. The association of early childhood caries and race/ethnicity among California preschool children, Journal of Public Health Dentistry, Vol. 63, No. 1, 38-46, 2007.

[38] R. I. Werneck, H. P. Lawrence, G. V. Kulkarni and D. Locker. Early childhood caries and access to dental care among children of Portuguese-speaking immigrants in the city of Toronto, Journal of the Canadian Dental Association, Vol. 74, No. 9, 805, 2008.

[39] S. Willems, J. Vanobbergen, L. Martens and J. De Maeseneer. The independent impact of household-and neighborhood-based social determinants on early childhood caries: a cross-sectional study of inner-city children, Family \& Community Health, Vol. 28, No. 2, 168-175, 2005.

[40] L. K. Wendt, A. L. Hallonsten, G. Koch and D. Birkhed. Oral hygiene in relation to caries development and immigrant status in infants and toddlers, European Journal of Oral Sciences, Vol. 102, No. 5, 269-273, 1994.

[41] S. C. Scrimshaw. Our multicultural society: implications for pediatric dental practice. Keynote speaker, 17th annual symposium, Denver, Colorado, Saturday, May 25, 2002, Pediatric Dentistry, Vol. 25, No. 1, 11, 2003.

[42] M. W. Kreuter, S. N. Lukwago, D. C. Bucholtz, E. M. Clark and V. Sanders-Thompson. Achieving cultural appropriateness in health promotion programs: targeted and tailored approaches, Health Education \& Behavior, Vol. 30, No. 2, 133-146, 2003.

[43] K. Hale. Oral health risk assessment timing and establishment of the dental home, Pediatrics, Vol. 111, No. 5 Pt 1, 1113, 2003.

[44] M. E. Nunn, T. Dietrich, H. K. Singh, M. M. Henshaw and N. R. Kressin. Prevalence of early childhood caries among very young urban Boston children compared with US children, Journal of Public Health Dentistry, Vol. 69, No. 3, 156-162, 2009.

[45] D. M. Krol. Educating pediatricians on children's oral health: past, present, and future, Pediatrics, Vol. 113, No. 5, e487-e492, 2004.

[46] K. M. Pierce, R. G. Rozier and W. F. Vann. Accuracy of pediatric primary care providers' screening and referral for early childhood caries, Pediatrics, Vol. 109, No. 5, e82-e82, 2002.

[47] D. Nutbeam. Health literacy as a public health goal: a 
challenge for contemporary health education and communication strategies into the 21st century, Health Promotion International, Vol. 15, No. 3, 259-267, 2000.

[48] R. C. Lefebvre and J. A. Flora. Social marketing and public health intervention, Health Education \& Behavior, Vol. 15, No. 3, 299-315, 1988.

[49] S. Grier and C. A. Bryant. Social marketing in public health, Annual Review of Public Health, Vol. 26, No. 1, 319-339, 2005.
[50] A. W. Block. 2000 Motor vehicle occupant safety survey, Vol. 2 Seat Belt Report, Schulman, Ronca and Bucuvalas, Inc.; Washington, DC: National Highway Traffic Safety Administration, U.S. Department of Transportation, November, Silver Spring, MD, 2001.

[51] A. F. Williams and J. A. K. Wells. The role of enforcement programs in increasing seat belt use, Journal of Safety Research, Vol. 35, No. 2, 175, 2004. 